\title{
Policy Analysis of Road Traffic Injury Prevention in Iran
}

\author{
Saber Azami-Aghdash ${ }^{1}$, Hassan Abolghasem Gorji ${ }^{2,3}$, Hosein Shabaninejad ${ }^{2}$, Homayoun Sadeghi-Bazargani ${ }^{4}$
}

${ }^{1}$ Ph.D. Candidate of Health Policy, Department of Health Services Management, School of Health Management and Information Sciences, Iran University of Medical Sciences, Tehran, Iran

${ }^{2}$ Ph.D. Assistant Professor, Department of Health Services Management, School of Health Management and Information Sciences, Iran University of Medical Sciences, Tehran, Iran

${ }^{3}$ Ph.D. Assistant Professor, Health Management and Economics Research Center, Iran University of Medical Sciences, Tehran, Iran

${ }^{4} \mathrm{Ph}$.D. Associate professor, Road Traffic Injury Research Center, Department of Statistics \& Epidemiology, School of Health, Tabriz University of Medical Sciences, Tabriz, Iran

Type of article: Original

\begin{abstract}
Introduction: Due to the large number of Road Traffic Injuries (RTIs) in Iran, authorities have implemented a number of policies for the prevention of RTIs. However, a scientific analysis of these policies has thus far been neglected. Therefore, this study was conducted for policy analysis of RTIs prevention in Iran.

Methods: This qualitative study with a case study approach was conducted in Iran during 2016 in two phases: First, by reviewing literature and documents of the past ten years, policies that have been executed to prevent RTIs in Iran were identified. In the second phase of the study, the identified policies were ranked by prioritization matrices. The two policies with the highest scores were selected. 'Policy triangle framework' was used for Policy analyzing. Stakeholders of these policies (42 people) were interviewed. Data were analyzed manually by implementing Content-Analysis methods.

Results: The policies of "pupil liaisons" and "safety belt" were selected for analysis from thirteen potential identified polices. The results of some studies revealed that safety belts had not been properly used in Iran (less than $80 \%$ ). There was an eight-year hiatus between the approval of the safety belts policy and implementation of this policy. Eight actors were identified for safety belts policy. Lack of diligence in implementation of the policy, failing to pay adequate attention to education and the culture of driving, and failing to select an organization for the implementation of the policy, were identified as the main weaknesses of this policy. For 'pupil liaisons' policy, five actors were identified. Following the implementation of this policy, the number of penalties was reduced $(17.9 \%)$. Neglecting scientific findings and individual-based nature of the policy were identified as the primary weaknesses of this policy.

Conclusions: Taking serious measures to properly execute the policy, educating people, selecting an efficient organization that is responsible for the implementation of the policies, and using international experience are the measures that can be taken to reduce the number of RTIs in the country.

Keywords: Road Traffic Injuries, Prevention, Policy analysis, Policy triangle framework
\end{abstract}

\section{Introduction}

Road Traffic Injuries (RTIs) are the primary cause of death and permanent disability worldwide, particularly in Low and Middle Income countries (LIMCs) (1-4). A large number of people who are taken into the emergency departments of hospitals are injury cases caused by RTIs $(1,5)$. Such accidents impose huge direct and indirect costs on the shoulders of government and society not to mention the personal loss and tragedy to families. (6). It is estimated that two million people are killed and fifty million others are injured in RTIs each year (7). It is predicted

\section{Corresponding author:}

Assistant Professor Dr. Hassan Abolghasem Gorji, Department of Health Services Management, School of Health Management and Information Sciences, Iran University of Medical Sciences, Tehran, Iran.

Tel: +98.9125267591, Email: gorji.h@iums.ac.ir

Received: April 30, 2016, Accepted: July 24, 2016, Published: January 2017

iThenticate screening: July 19, 2016, English editing: September 17, 2016, Quality control: November 04, 2016

(C) 2017 The Authors. This is an open access article under the terms of the Creative Commons Attribution-NonCommercialNoDerivs License, which permits use and distribution in any medium, provided the original work is properly cited, the use is non-commercial and no modifications or adaptations are made. 
that an increase of $65 \%$ will be observed in these figures in the next twenty years (8). In Iran, RTIs are the first cause of injury and the second cause of death $(9,10)$. On average, each day 64 people are killed and 1,967 people are injured in RTIs in Iran (11-13). Historically, RTIs are often considered as accidents that happen to other people and are inevitable and unpreventable circumstances. However, the results of an extensive body of research have shown that RTIs are preventable $(14,15)$. It is a conclusion that has been confirmed by all experts and actors in this field $(16,17)$. In High Income Countries (HICs), effective interventions have been taken, to reduce the number of RTIs. These interventions include speed control laws, the banning of drinking alcohol before driving, the necessity of using safety belt and child safety car seat, and improving the conditions of roads and vehicles (18-20). Similar to other LIMCs, a large number of interventions have been executed in order to reduce the number of RTIs (21, 22). According to a 2009 study by Soori and colleagues, the most outstanding problem in the execution of traffic policies is the lack of proper policy-making (23). Since a large number of policies have been executed in order to prevent the growth of RTIs in Iran, this study was conducted for a policy analysis of these preventive policies.

\section{Material and Methods}

This study was conducted in 2016 to analyze RTIs prevention policies in Iran. 'Policy triangle framework' was used for policy analysis.

\subsection{Policy triangle framework}

Policy triangle framework was designed in 1994 by Walt and Gilson for the analysis of health sector policies. In 2008 Walt and colleagues made some slight changes to this framework. This model covers four general areas: content, context, actors, and policy-making process. Content includes policy objectives, operational policies, etc. Actors refer to acting and influential individuals and organizations. Context refers to social, economic, political, cultural, and other environmental conditions. Process includes four sections: agenda setting, policy formulation, policy implementation, and policy evaluation (24). In this study, initially, RTIs prevention literature and documents of the past ten years were gathered from data bases, websites, organizational reports, and documents of acting organizations. In the next phase of study, policies which had been identified, using opinions of experts and stakeholders were ranked by prioritization matrices. After the ranking of policies, the two policies with the highest priority were selected. Then, these policies were analyzed by policy triangle framework.

\subsection{Policy identifying}

In order to identify policies, literature review and document analysis methods were used.

\subsubsection{Literature review}

In this phase of study, online articles and reports were collected. These data were gathered from websites, search engines, libraries, and various data bases. Both English data bases (Scopus, PubMed, and Google scholar) and Persian data bases (MagIran, SID, IranMedex, IranDoc) were used for the collection of data. The keywords of 'road, Iran, prevention, traffic collision injuries, road traffic injury, road traffic crashes, traffic accidents' and their Persian equivalents were used to collect the data. Also, the published hard copy versions of magazines, articles (reference of reference), reports, and documents were used, to gather the data.

\subsubsection{Document analysis}

In this phase of study, documents whose online versions were not accessible were collected from offices. Documents of RTIs prevention were collected from organizations which were involved in traffic planning, including Traffic Police, parliament (Majlis), Ministry of Roads and Transportation, Ministry of Industry, Ministry of Health and Medical Education, Ministry of Culture and Islamic Guidance, Ministry of Education, Medical jurisprudence Organization, Central Insurance Organization, Ministry of Interior, Red Crescent, and Emergency Department.

\section{3. Ranking of policies}

In this phase, the identified policies in the previous phase of the study were ranked by using prioritization matrices. This was determined on three indices: importance, relevance to RTIs prevention, and suitability for policy analysis. This ranking was determined on the basis of views of 42 experts and actors in this area. In this phase, 'pupil liaisons' policy and 'safety belt' policy (necessity of using safety belts), which had the highest scores, were selected for analysis in the next phase.

\subsection{Data collection}

In order to collect the data, three methods were used: semi-structured interviews, published reports and document analysis.

2.4.1. Semi-structured interviews

Participants of the interviews were a number of actors and experts in the RTIs prevention field, and from various organizations, including Traffic Police, Ministry of Health and Medical Education, Ministry of Roads and 
Transportation, Ministry of Industry, Ministry of Culture and Islamic Guidance, Ministry of Education, Medical Jurisprudence Organization, Central Insurance Organization, Ministry of Interior, Red Crescent, Emergency Department, and Law Enforcement Forces. These groups of people were specifically selected for their knowledge and experience in this area. Three criteria were taken into account for the selection of this group of people: having a position related to RTIs prevention, having sufficient knowledge in fields related to RTIs (authors, correspondents, report writers, etc.), and having the motivation to participate in the study. Purposive sampling method was used to select participants. In this method, people with the highest degree of knowledge and expertise in this field are selected in order to provide comprehensive information for the study $(25,26)$. The process of data gathering continued until the time that researchers of the study felt that no new information could be obtained. This phase of study was conducted by the participation of 25 people. In the interviews, a number of questions were used that had been designed by the help of experts and reviewing literature. Each interview took between 60 and 90 minutes. Participants of the study attended these interviews voluntarily. They were informed that they were free to leave the study at any moment they wished. The objectives of the study were explained to the participants before interviews.

\subsubsection{Published articles and reports}

In this phase of the study, online articles and reports on "pupil liaisons" and "safety belt" policies were collected. Results obtained from reviewing the literature were combined in policy identification phase.

\subsubsection{Documents analysis}

Eight organizational and governmental documents of "pupil liaisons" policies and "safety belt" policies were examined. This was done after obtaining permission from respected authorities and observing the principles of confidentiality. This was conducted by two researchers of the study.

\subsection{Data analysis}

Data obtained from the literature, documents, and semi-structured interviews were manually analyzed by ContentAnalysis methods. Codification of data was carried out by two researchers of the team.

\section{Results}

\subsection{Ranking (prioritization) of policies}

After reviewing the literature and documents, thirteen policies of RTIs prevention were identified. These policies were ranked on the basis of the views of forty two experts and actors of this field. At this stage, "pupil liaisons" policy with an average score of 14 (out of 15) and "safety belt" policy with an average score of 13 (out of 15) were selected for analysis in the next stage of study.

\subsection{Context}

3.2.1. An overall picture of RTIs in Iran

According to the 2015 World Health Organization (WHO) report, the number of fatalities caused by RTIs in Iran was 17,994 in 2013-2014 (according to information provided by Iranian officials). However, according to an estimation made by WHO, the number of fatalities caused by RTIs in Iran was higher (24,896 cases). Among these fatalities, $77 \%$ were men and $23 \%$ were women. According to the estimations of WHO, number of fatalities is 32.1 in 100 thousand people. According to this report, the highest numbers of deaths have been caused by accidents involving 4-wheeled passenger cars and light vehicles (24\%) and pedestrians (23\%). Based on the information provided in this report, the number of fatalities caused by RTIs has reduced from 40 deaths in every 100 thousand people in 2005 to 24 deaths in every 100 thousand people in 2014 (27).

\subsubsection{Using safety belts by Drivers in Iran}

According to a 2015 WHO report, $85 \%$ of Iranian people sitting in the front seat of cars and $10 \%$ of passengers sitting in the back seats used safety belts. The results of some studies in Iran have been given in table 1. As can be seen, the percentages of using safety belts by drivers and passengers are different (between $50 \%$ and $77.9 \%$ ).

\subsubsection{Pupil liaisons}

A Pupil Liaisons policy was introduced for students of elementary and guidance schools. The aim of this policy was to improve a culture of safety and social discipline among students and their parents, to enhance responsibility and self-confidence among students, to teach students safety and traffic points, to familiarize students with those law violations that might cause accidents, and to teach students how to respect laws and social regulations. The aim of this policy was to reduce the number of traffic law violations and the subsequent damages which might be caused by these violations. The execution of this policy began in 2007. The Pupil Liaisons approach, trains pupils to remind drivers of traffic law violations in cases where drivers do not observe traffic laws. They were trained to carry out their duty in a respectful way, and assigned to report such traffic law penalties in necessary cases. These pupil liaisons were expected to do this duty in areas inside and outside the cities (28). 
Table1. The results of some studies about using safety belts by drivers and passengers in Iran

\begin{tabular}{|c|c|c|}
\hline $\begin{array}{l}\text { Ref. } \\
\text { no. }\end{array}$ & Participants & Results \\
\hline 41 & $\begin{array}{l}\text { All car occupants injured in RTAs }(\mathrm{n}= \\
822) \text { who were transported to hospital and } \\
\text { hospitalized for more than } 24 \text { hours from } \\
\text { March } 2012 \text { to March } 2013\end{array}$ & $\begin{array}{l}\text { A total of } 560 \text { patients used seat belts }(68.1 \%) \text {. The unbelted } \\
\text { occupants were younger }(28 \text { years vs. } 38 \text { years) and had } \\
\text { more frequently sustained head, abdomen and multiple } \\
\text { injuries }(p=0.01, p=0.01 \text { and } p=0.009 \text {, respectively) }\end{array}$ \\
\hline 42 & College students & More than $50 \%$ of college students traveled unbelted. \\
\hline 43 & Cars and taxi drivers $(\mathrm{n}=10,752)$ & $\begin{array}{l}\text { The rate of seat belt use was } 70.9 \% \text {, and was significantly } \\
\text { higher in females, elders and on freeways and significantly } \\
\text { less in afternoon hours }\end{array}$ \\
\hline 44 & Drivers and front passengers & $\begin{array}{l}77.9 \% \text { of drivers and } 43.7 \% \text { of front passenger had seat-belts } \\
\text { fastened. More women used seat-belts than did men while } \\
\text { driving but fewer as front-seat passengers. }\end{array}$ \\
\hline 45 & 15 to 44 -years old people & The rate of seat belt use was estimated to be $54.4 \%$ \\
\hline 46 & Vehicles drivers $(\mathrm{n}=10.255)$ & The overall rate of seat belt use being $51.8 \%$. \\
\hline
\end{tabular}

Table 2. The summary of results related to the content of "safety belt" and "police assist" policies

\begin{tabular}{|c|c|c|}
\hline Content & Safety belt policy & Pupil liaisons \\
\hline Law & Yes & No \\
\hline Year of ratification & 1997 & 2006 \\
\hline Year of execution & 2005 & 2007 \\
\hline $\begin{array}{l}\text { Currently being } \\
\text { executed }\end{array}$ & Yes & Yes \\
\hline $\begin{array}{l}\text { Ratifying } \\
\text { organization }\end{array}$ & Parliament (Majlis) & $\begin{array}{l}\text { Ministry of Education and Traffic police } \\
\text { that executed this policy }\end{array}$ \\
\hline Executive directive & Executive directive: $18 / 3 / 2001,25 / 6 / 2005$ & - \\
\hline Target group & $\begin{array}{l}\text { Drivers and passengers sitting in the front seat in } \\
\text { inter-city roads, ring roads, and highways in the } \\
\text { cities }\end{array}$ & $\begin{array}{l}\text { Pre-school and elementary school students } \\
\text { as well as first grade guidance school } \\
\text { students }\end{array}$ \\
\hline $\begin{array}{l}\text { Proposing } \\
\text { organization }\end{array}$ & Traffic police of law enforcement forces & Traffic police of law enforcement forces \\
\hline Objective & $\begin{array}{l}\text { Reducing the number of deaths and injuries and } \\
\text { also economic losses caused by driving accidents }\end{array}$ & $\begin{array}{l}\text { Improve the culture of safety and social } \\
\text { discipline among students and their parents, } \\
\text { to enhance responsibility and self- } \\
\text { confidence among students, to teach } \\
\text { students safety and traffic points, to help } \\
\text { students become accustomed to those law } \\
\text { violations that might cause accidents, and to } \\
\text { teach students how to respect laws and } \\
\text { social regulations }\end{array}$ \\
\hline $\begin{array}{l}\text { Summary of the } \\
\text { manner of execution }\end{array}$ & $\begin{array}{l}\text { All owners of cars are required to equip their cars } \\
\text { with standard safety belts in the front seat for } \\
\text { drivers and passengers. The use of safety belts } \\
\text { for drivers and passengers in the front seat is } \\
\text { necessary in inter-city roads, highways in the } \\
\text { cities, and ring roads. Children under } 12 \text { should } \\
\text { not sit in the front seat. Technical check-up } \\
\text { license will not be issued for vehicles which do } \\
\text { not have safety belts in the front seats. }\end{array}$ & $\begin{array}{l}\text { The person in charge of executing "pupil } \\
\text { liaisons" policy holds educational sessions } \\
\text { for students and parents at the beginning of } \\
\text { school year. Interested students are invited } \\
\text { to participate in the policy. Membership } \\
\text { cards are issued for students who are } \\
\text { interested to participate in the plan. These } \\
\text { students attend training courses that are } \\
\text { held by the presence of traffic police at } \\
\text { schools. After these training courses, these } \\
\text { pupil liaisons are obliged to remind drivers } \\
\text { of traffic law violations in cases that drivers } \\
\text { do not observe traffic laws. They were } \\
\text { expected to do this by a respectful language }\end{array}$ \\
\hline
\end{tabular}




\subsection{Content}

The summary of results related to the content of "safety belt" and "pupil liaisons" policies is shown in Table 2 .

\subsection{Actors}

Eight actors were identified for safety belts policy included: Traffic police, Ministry of Interior, Ministry of Industry and Mines, Ministry of education, Ministry of Culture and Islamic Guidance, Ministry of Roads and Transportation, Ministry of justice and Management and Planning Organization. five actors were identified for 'pupil liaisons' policy included: Traffic Police, Ministry of Education, Ministry of Culture and Islamic Guidance, Management and Planning Organization, Parent-teacher council.

\subsection{Policy-making process}

Policy-making process consists of four parts: agenda setting, policy formulation, policy implementation, and policy evaluation. A summary of these parts has been given in table 3 .

The most important strengths and weaknesses of "safety belt" and "pupil liaison" policy have been given in table 4 . These are based on the views of interviewed participants.

Table 3. Summary of policy-making processes of "safety belt" and "pupil liaisons" policies in Iran

\begin{tabular}{|c|c|c|}
\hline Policies & Safety belt policy & Pupil liaisons \\
\hline Agenda setting & $\begin{array}{l}\text { Increase RTIs, The identification of safety belt as } \\
\text { an effective tool for reducing damages in } \\
\text { accidents, The need for increasing safety } \\
\text { equipment in vehicles, Pressure from actors }\end{array}$ & $\begin{array}{l}\text { Increase RTIs, The need for the } \\
\text { participation of people, The need for } \\
\text { encouraging children to observe safety } \\
\text { issues, The need for inter-sectional } \\
\text { cooperation, The role of children in the } \\
\text { implementation of traffic laws }\end{array}$ \\
\hline $\begin{array}{l}\text { Policy } \\
\text { formulation }\end{array}$ & $\begin{array}{l}\text { Policy offer: by Traffic Police, Approval of law: in } \\
\text { parliament (Majlis), Designing an executive } \\
\text { directive: by Ministry of Interior, Ministry of } \\
\text { Justice, Ministry of Industry and Mines, Ministry } \\
\text { of Roads and Transportation, Approval of } \\
\text { executive directive: by board of government }\end{array}$ & $\begin{array}{l}\text { By Traffic Police and Ministry of } \\
\text { Education }\end{array}$ \\
\hline $\begin{array}{l}\text { Policy } \\
\text { implementation }\end{array}$ & $\begin{array}{l}\text { Coercion to using safety belt: from up to down } \\
\text { model by Traffic police }\end{array}$ & $\begin{array}{l}\text { Voluntary. Parallel (up to down and down } \\
\text { to up) }\end{array}$ \\
\hline $\begin{array}{l}\text { Policy } \\
\text { evaluation }\end{array}$ & $\begin{array}{l}\text { The results of a } 2009 \text { study conducted by Soori et } \\
\text { al. showed that after the implementation of "safety } \\
\text { belt" law, the percentage of deaths caused by } \\
\text { accidents reduced from } 13 \% \text { in the first year to } \\
9.7 \% \text { in the second year }(20)\end{array}$ & $\begin{array}{l}\text { The results of a } 2010 \text { study conducted by } \\
\text { Soori et al showed that after the } \\
\text { implementation of "pupil liaisons" } \\
\text { policy, number of penalties reduction was } \\
17.9 \%(19)\end{array}$ \\
\hline
\end{tabular}

Table 4. A summary of the most important strengths and weaknesses of "safety belt" and "pupil liaisons" policies in Iran on the basis of views of interviewed participants (25 participants)

\begin{tabular}{|l|l|l|}
\hline \multirow{2}{*}{$\begin{array}{l}\text { Strengths and } \\
\text { weaknesses }\end{array}$} & Policies & "Pafety belt" policy \\
\cline { 2 - 3 } Weaknesses & $\begin{array}{l}\text { Neglecting the implementation of policy in the second } \\
\text { year and the following years, Neglecting educational } \\
\text { issues and the culture of using safety belt, The absence } \\
\text { of an organization for the implementation of law } \\
\text { (decision-making, implementation, and control), The } \\
\text { ineffectiveness of fines for non-use of safety belts } \\
\text { during driving, Non-standard safety belts }\end{array}$ & $\begin{array}{l}\text { Not using scientific findings (based on } \\
\text { scientific findings, the education of } \\
\text { traffic laws for children under 8-9 is } \\
\text { not useful), Individual-based nature of } \\
\text { the policy, Neglecting the } \\
\text { implementation of the policy after } \\
\text { some time }\end{array}$ \\
\hline Strengths & $\begin{array}{l}\text { The involvement and participation of various } \\
\text { organizations, The increase of using safety belts, The } \\
\text { increase of paying more attention to safety issues in } \\
\text { vehicles }\end{array}$ & $\begin{array}{l}\text { The increase of inter-sectional } \\
\text { cooperation (traffic police and Ministry } \\
\text { of Education), Using potential powers } \\
\text { and capacities of society, Increasing the } \\
\text { culture of safety }\end{array}$ \\
\hline
\end{tabular}




\section{Discussion}

After examining literature and documents, thirteen policies whose aim was to reduce RTIs were identified. "Pupil liaisons" and "safety belt" policies were selected for policy analysis. According to a 2015 WHO report, the number of deaths caused by RTIs in Iran was 24,896 in 2013-2014. Among deaths caused by accidents worldwide (in every 100 thousand people), only six countries had a higher death rate than Iran. According to this report, the efficiency of laws and policies was 70\% (7 from 10) (27). Also, it was reported that $85 \%$ of people sitting in the front seat and $10 \%$ of passengers sitting in the back seats use safety belts. The results of studies have shown that safety belts are not properly used in Iran. A review of literature showed that a safety belt is an effective tool for reducing the damage that is caused by RTIs. Therefore, it is necessary to take serious measures for the implementation of "safety belt" policy. Because of the high number of RTIs in Iran, a number of intervention programs have been conducted in recent years, to reduce the number of such accidents. According to a report issued by Traffic Police of Law Enforcement Forces, some interventions and programs such as heavy punishments for high speed, the improvement of safety equipment, and the increase in fines have been relatively effective in reducing the number of RTIs. Other interventions such as increasing the budget of Traffic Police, repairing roads, using CCTV cameras, improving medical care, and improving structural facilities (particularly in railroads) were not significantly successful in reducing the number of RTIs (11). Therefore, it is necessary to reconsider interventions and policies, and to solely employ only those policies which are effective in preventing RTIs.

The policy which made safety belts necessary was approved by parliament (Majlis) in 1997. The executive directive of this law was designed in 2000. In 2004, this directive was reviewed and notified for implementation. There was a period of eight years between approval and implementation of the policy. Because the conditions may change over such a long period between approval and implementation, the policy might lose its effectiveness (29, 30). Eight organizations were selected as actors for "safety belt" policy. A 2009 study by Soori and colleagues identified fifteen organizations (Ministry of Roads and Transportation, Ministry of Industry, Ministry of Health, Traffic Police, Ministry of Science and Higher Education, Ministry of Education, Medical Jurisprudence Organization, Ministry of Interior, Red Crescent, Emergency Department, Law Enforcement Forces, Islamic republic of Iran Broadcasting, Ministry of Justice) as the actors in issues related to RTIs in Iran (23). Among the eight identified actors in this study, six cases were consistent with the results of the study conducted by Soori. Traffic Police and the government cabinet played a key role in the approval and implementation of "safety belt" policy. These results are consistent with the results of the study conducted by Soori et al which identified Traffic Police and the presidential office as the key bodies for dealing with RTIs. Therefore, it seems that Traffic Police can play an integral part in preventing RTIs if it is given the power and enough resource. The approval of effective laws and a clear definition of duties and also the direct support of presidential office can help Traffic Police to achieve this objective. In many countries, traffic police and central government take a responsible role in dealing with RTIs (31-33). There is no doubt that other organizations must support traffic police, because a systematic approach and inter-sectional cooperation is crucial to achieving RTIs prevention (34-36). A research conducted by Soori and colleagues was the only study that had evaluated the effectiveness of "safety belt" policy (37). The results of this study showed that after the implementation of "safety belt" law, the number of deaths caused by RTIs reduced from 13\% (in the year before the implementation of policy) to $9.7 \%$ in the first year and $11.3 \%$ in the second year after the implementation of law. According to these results, the number of deaths in the second year was $1.6 \%$ higher than the number of deaths in the first year following the implementation of policy. Authors concluded that "safety belt" policy had been particularly effective in the first year after the implementation of policy. However, it is necessary to make every effort to encourage people to respect this law continuously and in all conditions. People should be encouraged to become accustomed to these laws. s. Similarly, participants of this study believed that neglecting the proper implementation of the policy in the second year and following years is one of the main weaknesses of "safety belt" policy. This is consistent with the results of a 2009 study, conducted by Khorasani-Zavareh and colleagues (38). Also, participants of this study believed that people had not been properly taught how to use safety belts. Therefore, it is necessary to educate people on how to use safety belts and make it a culture among people. We should consider that educational interventions can be leads to an increase in knowledge of people, but cannot be effective if it does not change their behavior (39).

The implementation of "Pupil liaisons" policy started in 2007 by the cooperation of Traffic Police, heads of schools, and students. In this policy, nine cases of traffic law penalties were taught to students (excessive speed, overtaking ban, maze movement, talking on the phone while driving, talking to others while driving, driving during tiredness and sleeplessness, not using safety belts, eating while driving, and not paying attention to signs and traffic lights). Pupil liaisons are required to remind drivers of any traffic law penalties in cases where drivers do not observe traffic 
laws. In necessary cases, these pupil liaisons are obliged to report such penalties. The execution of such policies could help students to become accustomed to safety issues and traffic laws, to improve social responsibility, to strengthen self-confidence, and to propagate the culture of respect for social laws. These can lead to a reduction in traffic law penalties and damages and losses caused by these penalties. According to Iran Census Organization, in the year of 2014-2015, 9,241,825 students were studying at elementary and guidance school levels. The participation of students in RTIs prevention programs can produce positive results in short terms and log terms. The 2010 study conducted by Soori and colleagues evaluated the effectiveness of "Pupil liaisons" policy. The results of this study showed that the implementation of this policy led to a $17.9 \%$ reduction in the number of traffic law penalties. The maximum number of penalties was related to eating and drinking while driving. Apart from "talking on the phone while driving", other traffic law penalties reduced once the policy had begun (28). Considering the majority of these pupil liaisons will be future drivers, it can be expected that the number of traffic law penalties will reduce in future, and the roads and streets will be safer. Therefore, the increase of a target group, together with an increase in support, can have short-term and long-term positive results. Many of the participants of the study believed that elementary students who are under 10 years old, should not be the target of this policy. They considered it as a weakness of "pupil liaisons" policy. They believed that such education creates a false confidence among children. The results of an objective 2002 study conducted by Duperrex and colleagues showed that such policies do not produce positive results among students who are under 10 years old (40). In order to solve such problems, it was recommended that the policies be taught during holidays and summer, because there is a sharp increase in the amount of travel in these periods. Also, these educational policies are generally directed towards children who are older than 10 years old. Based on the results obtained from reviewing literature, and our best knowledge, this research was the first to objectively analyze the RTIs prevention policies. However, limited access to documents was the important limitation of this study.

\section{Conclusions}

Due to the critical role of education in RTIs prevention, "Pupil liaisons" policy was executed to use all current capacities. Safety belts are not properly used by drivers and passengers in Iran. Serious measures must be taken and educational programs must be held to encourage people to use safety belts. Moreover, an organization with sufficient power and budget must take the responsibility for the execution of such RTIs prevention policy. Using international experience about "Pupil liaisons", holding educational sessions during holidays and summer, and executing this policy for children above 10 years old are factors that can contribute to the success of these policies. Policy analyses of other RTIs prevention interventions are recommended for future studies.

\section{Acknowledgments:}

This study was part of a PhD thesis supported by School of Health Management, Iran University of Medical Sciences (Grant no: IUMS/SHMIS_1394/9221557209). We are grateful to Mohammad Mohseni (Ph.D. candidate of health policy) who helped us in preparation and making significant improvement to the manuscript.

\section{Conflict of Interest:}

There is no conflict of interest to be declared.

Authors' contributions:

All authors contributed to this project and article equally. All authors read and approved the final manuscript.

\section{References:}

1) Rus Ma D, Peek-Asa C, Baragan EA, Chereches RM, Mocean F. Epidemiology of Road Traffic Injuries Treated in a Large Romanian Emergency Department in Tirgu-Mures Between 2009 and 2010. Traffic Inj Prev. 2015; 16(8): 835-41. doi: 10.1080/15389588.2015.1030501. PMID: 25830568.

2) Bachani AM, Koradia P, Herbert HK, Mogere S, Akungah D, Nyamari J, et al. Road traffic injuries in Kenya: the health burden and risk factors in two districts. Traffic Inj Prev. 2012; 13(1): 24-30. doi: 10.1080/15389588.2011.633136. PMID: 22414125.

3) Azami-Aghdash S, Abolghasem Gorji H, Sadeghi-Bazargani H, Shabaninejad H. Epidemiology of Road Traffic Injuries in Iran: Based on the Data from Disaster Management Information System (DMIS) Of the Iranian Red Crescent. Iran Red Crescent Med J.(in press):e38743.

4) Azami-Aghdash S, Abolghasem Gorji H, Sadeghi-Bazargani H, Shabaninejad H. Injury epidemiology in Iran: a systematic review. J Inj Violence Res. 2017;9(1):1-14 
5) Sadeghi-Bazargani H, Azami-Aghdash S, Ziapour B, Deljavan R. Trauma-related Therapeutic Procedures at Shohada Trauma Center in Tabriz. Trauma Mon. 2013; 17(4): 389-92. doi: 10.5812/traumamon.7737. PMID: 24350134, PMCID: PMC3860659.

6) Ainy E, Soori H, Ganjali M, Le H, Baghfalaki T. Estimating Cost of Road Traffic Injuries in Iran Using Willingness to Pay (WTP) Method. PLoS One. 2014; 9(12): 112721. doi: 10.1371/journal.pone.0112721. PMID: 25438150, PMCID: PMC4249801.

7) Short MM, Mushquash CJ, Bedard M. Motor vehicle crashes among Canadian Aboriginal people: a review of the literature. Can J Rural Med. 2013; 18(3): 86-98. PMID: 23806432.

8) WHO. World report on road traffic injury prevention. Geneva: World Health Organization. 2004.

9) Jafari MJ, Hokmabadi R, Soori H. The Status of Road Safety in Iran during 2001-2006. J Heal Safe Work. 2013; 3(1): 1-12.

10) Lankarani KB, Sarikhani Y, Heydari ST, Joulaie H, Maharlouei N, Peimani P, et al. Traffic accidents in Iran, a decade of progress but still challenges ahead. Med J Islam Repub Iran. 2014; 28: 96. PMID: 25664297, PMCID: PMC4301220.

11) Nikzad F. First book in road traffic injury and its damages, causes and suggestion for prevention of outcomes. Recommended with republic of Iranian traffic police. 1 ed Tehran. 2006.

12) Sadeghian F, Khosravi A, Emamian M, Younesian R, Emamian M, Khosravi A, et al. The pattern of road traffic injuries and related factors in Shahrood, Iran. Payesh. 2008; 7(3): 225-33.

13) Sadeghi-Bazargani H, Ayubi E, Azami-Aghdash S, Abedi L, Zemestani A, Amanati L, et al. Epidemiological Patterns of Road Traffic Crashes During the Last Two Decades in Iran: A Review of the Literature from 1996 to 2014. Arch Trauma Res. InPress(InPress). e32985. doi: 10.5812/atr.32985.

14) Jaung MS, Yu S, Stallones L, Xiang H. Road traffic injuries among middle school students in a rural area of China. Traffic Inj Prev. 2009; 10(3): 243-51. doi: 10.1080/15389580902775147. PMID: 19452366.

15) Chandran A, Sousa TR, Guo Y, Bishai D, Pechansky F; Vida No Transito Evaluation Team. Road traffic deaths in Brazil: rising trends in pedestrian and motorcycle occupant deaths. Traffic Inj Prev. 2012; 13(1): 11-6. doi: 10.1080/15389588.2011.633289. PMID: 22414123.

16) Rad S. The survey of human error and its relationship with driving accident. Tolo e Shargh. 2009; 8(3): 279.

17) Manno M, Rook A, Yano-Litwin A, Maranda L, Burr A, Hirsh M. On the road with injury prevention--an analysis of the efficacy of a mobile injury prevention exhibit. J Trauma. 2011; 71(5 Suppl 2): 505-10. doi: 10.1097/TA.0b013e31823a49bc. PMID: 22072036.

18) Bunn F, Collier T, Frost C, Ker K, Roberts I, Wentz R. Area-wide traffic calming for preventing traffic related injuries. Cochrane Database Syst Rev. 2003; 1: CD003110. doi: 10.1002/14651858.CD003110. PMID: 12535454.

19) Peden M. Global collaboration on road traffic injury prevention. Int J Inj Contr Saf Promot. 2005; 12(2): 85-91. doi: 10.1080/15660970500086130. PMID: 16156532.

20) Pless B. Road traffic injury prevention. BMJ. 2004; 328(7444): 846. doi: 10.1136/bmj.328.7444.846. PMID: 15073051, PMCID: PMC387463.

21) Khorasani-Zavareh D, Shoar S, Saadat S. Antilock braking system effectiveness in prevention of road traffic crashes in Iran. BMC Public Health. 2013; 13: 439. doi: 10.1186/1471-2458-13-439. PMID: 23642097, PMCID: PMC3649935.

22) Soori H, Royanian M, Zali AR, Movahedinejad A. Study of changes on Road Traffic Injury Rates, before and after of Four Interventions by Iran Traffic Police. Pajoohandeh. 2009; 14(1): 15-20.

23) Soori H, Movahedinejad A, Mahfozphoor S, Movahedi M, Rezazadeh Azari M, Hatamabadi H, et al. A Practical Model of Political Mapping in Road Traffic Injury in Iran in 2008. Hakim. 2009; 12(3): 1-9.

24) Walt G, Shiffman J, Schneider H, Murray SF, Brugha R, Gilson L. 'Doing' health policy analysis: methodological and conceptual reflections and challenges. Health Policy Plan. 2008; 23(5): 308-17. doi: 10.1093/heapol/czn024. PMID: 18701552, PMCID: PMC2515406.

25) Benoot $\mathrm{C}$, Hannes $\mathrm{K}$, Bilsen J. The use of purposeful sampling in a qualitative evidence synthesis: A worked example on sexual adjustment to a cancer trajectory. BMC Med Res Methodol. 2016; 16: 21. doi: 10.1186/s12874-016-0114-6. PMID: 26891718, PMCID: PMC4757966.

26) Cleary M, Horsfall J, Hayter M. Data collection and sampling in qualitative research: does size matter? J Adv Nurs. 2014; 70(3): 473-5. doi: 10.1111/jan.12163. PMID: 24450874.

27) WHO. Global status report on road safety 2015. Geneva. 2015.

28) Souri H, Eyni E, Montazeri A, Omidvari S, Jahangiree AR, Shiran GHR. The role of pupil liaisons' on traffic penalties and road traffic injuries. Payesh. 2010; 9(4): 339-48. 
29) Touati N, Roberge D, Denis JL, Pineault R, Cazale L, Tremblay D. Governance, health policy implementation and the added value of regionalization. Healthc Policy. 2007; 2(3): 97-114. doi: 10.12927/hcpol.2007.18706. PMID: 19305724, PMCID: PMC2585452.

30) Buse K, Mays N, Walt G. Understanding public health. Making health policy. Edited by: Black N, Raine N. Open University Press. 2005.

31) Newstead SV, Cameron MH, Leggett LM. The crash reduction effectiveness of a network-wide traffic police deployment system. Accid Anal Prev. 2001; 33(3): 393-406. doi: 10.1016/S0001-4575(00)00053-1. PMID: 11235801 .

32) Rosenbloom T, Pereg A, Perlman A. Compliance with traffic laws by traffic police officers, non-traffic police officers, and civilian drivers. Traffic Inj Prev. 2014; 15(5): 446-50. doi: 10.1080/15389588.2013.834531. PMID: 24678566.

33) Satapathy D, Behera T, Tripathy R. Health status of traffic police personnel in brahmapur city. Indian J Community Med. 2009; 34(1): 71-2. doi: 10.4103/0970-0218.45380. PMID: 19876462, PMCID: PMC2763644.

34) Loo BP, Chow CB, Leung M, Kwong TH, Lai SF, Chau YH. Multidisciplinary efforts toward sustained road safety benefits: integrating place-based and people-based safety analyses. Inj Prev. 2013; 19(1): 58-63. doi: 10.1136/injuryprev-2012-040400. PMID: 23024168.

35) Stevenson M, Thompson J. On the road to prevention: road injury and health promotion. Health Promot J Austr. 2014; 25(1): 4-7. doi: 10.1071/HE13075. PMID: 24739772.

36) Khorasani-Zavareh D. System versus traditional approach in road traffic injury prevention: a call for action. J Inj Violence Res. 2011; 3(2): 61. doi: 10.5249/jivr.v3i2.128. PMID: 21498966, PMCID: PMC3134927.

37) Soori H, Nasermoadeli A, Ainy E, Movahedi M, Mehmandar M, Massoudei Nejhad M, et al. The effect of mandatory seat belt use legislations on mortalities from road traffic injuries in Iran. Hakim. 2009; 12(1): 48-54.

38) Khorasani-Zavareh D, Mohammadi R, Khankeh HR, Laflamme L, Bikmoradi A, Haglund BJ. The requirements and challenges in preventing of road traffic injury in Iran. A qualitative study. BMC Public Health. 2009; 9: 486. doi: 10.1186/1471-2458-9-486. PMID: 20030826, PMCID: PMC2811114.

39) Assailly JP. Road safety education: What works? Patient Educ Couns. 2015; S0738-3991(15)30098-7. doi: 10.1016/j.pec.2015.10.017. PMID: 26549168.

40) Duperrex O, Bunn F, Roberts I. Safety education of pedestrians for injury prevention: a systematic review of randomised controlled trials. BMJ. 2002; 324(7346): 1129. doi: 10.1136/bmj.324.7346.1129. PMID: 12003885, PMCID: PMC107905.

41) Mohammadzadeh M, Paravar M, Mirzadeh AS, Mohammadzadeh J, Mahdian S. Seat Belt Usage in Injured Car Occupants: Injury Patterns, Severity and Outcome After Two Main Car Accident Mechanisms in Kashan, Iran, 2012. Arch Trauma Res. 2015; 4(1): e22203. doi: 10.5812/atr.22203. PMID: 26064867, PMCID: PMC4460257.

42) Mohammadi G. Prevalence of seat belt and mobile phone use and road accident injuries amongst college students in Kerman, Iran. Chin J Traumatol. 2011; 14(3): 165-9. PMID: 21635804.

43) Nabipour AR, Khanjani N, Soltani Z, Akbari M. The rate of seat belt use and its related factors among car drivers in Tehran, Iran after imposing new regulations. Int J Inj Contr Saf Promot. 2014; 21(4): 348-54. doi: 10.1080/17457300.2013.833941. PMID: 24024478.

44) Sadeghnejad F, Niknami S, Hydarnia A, Montazeri A. Seat-belt use among drivers and front passengers: an observational study from the Islamic Republic of Iran. East Mediterr Health J. 2014; 20(8): 491-7. PMID: 25150356.

45) Akbari M, Nabipour A, Hesampour M, Khanjani N. The rate of safety belt use and its associated factors in 15 to 44-years old of Kerman in 2012. J Safe Prom Inj Preve. 2013; 1(3): 116-22.

46) Torkamannejad Sabzevari J, Khanjani N, Molaei Tajkooh A, Nabipour AR, Sullman MJ. Seat belt use among car drivers in Iranian safe communities: An observational study. Traffic Inj Prev. 2016; 17(2): 13441. doi: 10.1080/15389588.2015.1052138. PMID: 26065342. 